\title{
Aplicação da microalga Spirulina spp. em iogurte liofilizado
}

Application of microalgae Spirulina spp. in freeze-dried yogurt

\author{
I. M. Suyama ${ }^{1}$; L. Barison ${ }^{1}$; S. S. dos Santos²; C. M. Paraíso²; A. P. Stafussa ${ }^{2}$; G. \\ S. Madrona ${ }^{1 *}$ \\ ${ }^{1}$ Departamento de Engenharia de Alimentos, Universidade Estadual de Maringá, 87020-900,Maringá-Paraná, Brasil \\ ${ }^{2}$ Programa de Pós-Graduação em Ciência de Alimentos, Universidade Estadual de Maringá, 87020-900,Maringá- \\ Paraná, Brasil \\ *gsmadrona@uem.br
}

(Recebido em 04 de novembro de 2019; aceito em 14 de fevereiro de 2020)

\begin{abstract}
O presente trabalho teve como objetivo o estudo da produção de iogurte liofilizado enriquecido com a microalga Spirulina spp. e sua avaliação quanto às características físico-químicas, antioxidantes e aceitação sensorial. Duas formulações com concentrações distintas de Spirulina spp. $(0,25 \%$ e $0,50 \%)$ foram desenvolvidas tanto para o iogurte padrão quanto para o iogurte reconstituído (liofilizado com adição 1:3 $(\mathrm{m} / \mathrm{v})$ de iogurte e água). Os dados foram submetidos à análise de variância e as médias comparadas pelo teste de Tukey à $5 \%$ de significância. $\mathrm{O}$ iogurte enriquecido com a microalga obteve maior atividade antioxidante pelo método ABTS. O teor proteico do iogurte padrão aumentou de 3,65\% (amostra sem Spirulina spp.) para 4,14\% (amostra com 0,50\% de Spirulina spp.). Quanto à aceitabilidade, o iogurte reconstituído sem adição de Spirulina spp. apresentou as maiores notas, indicando que a liofilização realçou o sabor do iogurte. As amostras com a adição de Spirulina spp. tiveram menor aceitação devido, provavelmente, à sua coloração e sabor diferencial. A adição da microalga Spirulina spp. no iogurte liofilizado aumenta a atividade antioxidante e teor proteico.

Palavras-chave: Arthrospira platensis, Arthrospira maxima, proteína, antioxidantes.
\end{abstract}

The present work had as objective the study of the production of a powdered yogurt enriched with the microalgae Spirulina spp., and the evaluation of physic-chemical, antioxidant, and sensorial acceptance. Two formulations were developed with concentrations different from Spirulina spp. $(0.25 \%$ and $0.50 \%)$, for the standard yogurt and the reconstituted yogurt (lyophilized with 1: 3 (w/v) addition of yogurt and water). The obtained products were analyzed for physio-chemical characteristics, antioxidant activity and sensorial acceptance with the structured hedonic scale of nine points. The data were evaluated by ANOVA and Tukey test at $5 \%$ of significance. The yogurt enriched with the microalga obtained a higher antioxidant activity for the ABTS analysis, besides having increased the protein content of the standard yogurt from $3.65 \%$ (sample without Spirulina spp.) for $4.14 \%$ (sample with $0.50 \%$ of Spirulina spp.). Regarding the acceptance, the yogurt sample reconstituted without spirulina addition presented the highest notes, indicating that the lyophilization enhanced the yogurt flavor. Samples with the addition of Spirulina spp. were less accepted probably because of their color and differential taste. The addiction of Spirulina spp. in a powdered yogurt increases the antioxidant activity and protein content.

Keywords:Arthrospira platensis, Arthrospira maxima, protein, antioxidant.

\section{INTRODUÇÃO}

A busca por praticidade vem sendo cada vez mais desejada pela população em geral. Desta forma, as indústrias de alimentos têm introduzido no mercado, produtos de consumo rápido, que mantenham suas qualidades nutricionais, como frutas desidratadas, snacks integrais, iogurte com características funcionais, entre outros [1]. O iogurte é um produto que contém alta concentração de vitaminas, minerais, cálcio, proteínas, magnésio, potássio, fósforo e zinco, além de conter baixo teor de gorduras e ser mais facilmente aceito por indivíduos intolerantes a lactose [2].

Um dos principais obstáculos que as indústrias de alimentos enfrentam é manter a cadeia do frio. Isso porque é um processo que requer elevado investimento, que objetiva preservar e prolongar a vida de prateleira de produtos como iogurte, por exemplo [3]. Processos de desidratação e secagem podem ser uma alternativa viável para o aumento da vida de prateleira de produtos e redução de custos com a cadeia do frio. Esses processos possibilitam a redução da atividade de água dos 
produtos, o que dificulta o crescimento de microrganismos indesejáveis, facilitando, assim, o armazenamento e a praticidade [4].

A liofilização é um processo de desidratação de produtos que ocorre em certas condições de pressão e temperatura, permitindo que a água em estado sólido passe diretamente ao estado gasoso, pelo processo de sublimação. Esse método tem por objetivo estabilizar produtos mediante a redução da atividade de água, obtendo produtos de qualidade superior, fácil reconstituição e com um aumento na vida de prateleira [5]. Destaca-se ainda que para preservação de microrganismos, a liofilização é um dos processos mais aplicados atualmente [6]. Entretanto, é um processo ainda considerada de alto custo.

O aumento expressivo do uso de suplementos alimentares por parte dos consumidores é devido à ampliação de alimentos refinados, que combinados a um estilo de vida pouco saudável, aumentam a carência e a importância de uma suplementação imprescindível em nutrientes [7]. Muitos suplementos vêm sendo utilizados, como as microalgas Chlorella e Spirulina spp. O gênero Spirulina spp., também conhecido por Arthrospira platensis e Arthrospira maxima, compreende as cianobactérias, que são microalgas verde-azuladas e possuem como características serem fotossintéticas e autotróficas [8]. As microalgas produzem importantes produtos bioativos, tais como esteróis, polímeros, carotenoides e toxinas, as quais têm sido utilizadas para diversas aplicações, entre eles: fármacos, nutrição humana e animal e cosméticos [9].

A Spirulina spp. possui diversos benefícios para a saúde humana, como no tratamento de alergias, imunodeficiência, anemia, hiperglicemia, doenças virais e cardiovasculares, hiperlipidemia [10]. O gênero Spirulina spp. é considerado um alimento suplementar, sendo uma fonte rica de nutrientes, tais como vitaminas do complexo B, proteínas, clorofila, vitamina E, ômega-6 e vários minerais, entre eles manganês, potássio, cálcio, fósforo, magnésio [9].

Diante do cenário apresentado acima, o trabalho teve como objetivo desenvolver iogurtes enriquecidos com diferentes concentrações da microalga Spirulina spp., e avaliar suas características físico-químicas, teor de compostos bioativos e aceitação, frente ao processo de secagem por liofilização.

\section{MATERIAL E MÉTODOS}

\subsection{Material}

A microalga do gênero Spirulina spp. (Biovera BF), leite integral UHT (Líder), leite em pó integral (Ninho), açúcar cristal (União), cultura láctea (BioRich) e o saborizante foram adquiridos no comércio local da cidade de Maringá, Paraná, Brasil. Os demais reagentes utilizados nas análises foram de grau analítico.

\subsection{Produção e liofilização do iogurte}

O iogurte natural foi produzido misturando-se $1 \mathrm{~L}$ de leite, $0,16 \%$ de leite em pó e 6,0\% de açúcar. Após a homogeneização, a mistura foi pasteurizada $\left(60^{\circ} \mathrm{C} / 30 \mathrm{~min}\right)$, resfriada e mantida a $43^{\circ} \mathrm{C}$. Posteriormente foi adicionado $0,04 \%$ de cultura láctea e fermentado (incubadora de bancada microbiológica Sterelifer) a $45^{\circ} \mathrm{C}$, até a formação de coágulo (aproximadamente $4 \mathrm{~h}$ ). Por fim, o iogurte foi retirado da estufa e levado para a refrigeração $\left(5^{\circ} \mathrm{C}\right)$.

A partir do iogurte natural, foi elaborado o que denominamos de iogurte padrão (IP). O iogurte padrão foi separado em 3 porções iguais, sendo um sem adição de Spirulina spp. (IP0), e os outros adicionados de Spirulina spp. nas concentrações de 0,25\% (IP25) e 0,50\% (IP50). As mesmas formulações de iogurte padrão foram congeladas $\left(-15^{\circ} \mathrm{C} / 24 \mathrm{~h}\right)$ e submetidas ao processo de liofilização (liofilizador Christ -modelo alfa 1-4 LO Plus) operando a uma temperatura de $-50^{\circ} \mathrm{C}$ e em vácuo e pressão de 0,040 mbar por $48 \mathrm{~h}$. A partir do iogurte liofilizado, obteve-se iogurte reconstituído (IR), sem adição de Spirulina spp. (IR0), com adição de 0,25\% (IR25) e 0,50\% (IR50).

Os iogurtes IR0, IR25 e IR50 foram triturados em liquidificador doméstico por cerca de $20 \mathrm{~s}$. Para as análises, foram reconstituídos na proporção 1:3 ((m/v) de iogurte e água), a fim de alcançar a textura do iogurte antes de passar pelo processo de liofilização (proporção escolhida com base 
em testes preliminares). $\mathrm{O}$ iogurte foi produzido em replica e as análises foram realizadas em triplicata.

\subsection{Físico-químicas}

A determinação da acidez e pH foi realizada segundo Instituto Adolfo Lutz [11] em triplicata. O teor de sólidos solúveis totais ( ${ }^{\circ}$ Brix) foi medido por meio do refratômetro Modelo RX-5000 $\alpha$ a $25^{\circ} \mathrm{C}$.

\subsection{Composição centesimal}

A análise de cinzas, lipídeos, proteínas e umidade foram realizadas segundo Instituto Adolfo Lutz [11] em triplicata. A determinação do teor de carboidratos foi calculada pela diferença entre os demais constituintes.

\subsection{Determinação de cor instrumental}

A cor foi medida em colorímetro CR-400 Minolta Chromameter (Minolta Cia Ltda.), no espaço CIE L*a*b*, onde $\mathrm{L}^{*}=$ luminosidade, $\mathrm{a}^{*}=$ intensidade da cor vermelha a verde e $\mathrm{b}^{*}=$ intensidade da cor amarela a azul, calibrado com padrão branco. As análises foram realizadas em triplicata.

\subsection{Análises de compostos fenólicos totais e atividade antioxidante}

Para a realização das análises foi necessário realizar a precipitação das proteínas do iogurte com ácido tricloroacético 20\% em água, na proporção 1:1 [12]. As amostras foram submetidas à agitação por $30 \mathrm{~s}$ e incubadas a $42^{\circ} \mathrm{C}$ por $10 \mathrm{~min}$. Em seguida, foram centrifugadas por $15 \mathrm{~min}$ e o sobrenadante foi utilizado para as análises de compostos fenólicos totais e atividade antioxidante.

\subsubsection{Determinação de compostos fenólicos totais}

A determinação de compostos fenólicos totais (TPC) foi realizada utilizando os reagentes FolinCiocalteu e carbonato de sódio $\left(\mathrm{Na}_{2} \mathrm{CO}_{3}\right)$ [13, 14]. A absorbância foi verificada em um espectrofotômetro (Femto, 700 plus) a $725 \mathrm{~nm}$ após $30 \mathrm{~min}$ de incubação a $25^{\circ} \mathrm{C}$. O ácido gálico (EAG) foi utilizado como padrão para a curva de calibração. Os resultados foram expressos em $\mathrm{mg}$ de equivalente de ácido gálico por grama de produto (mg EAG.g $\left.{ }^{-1}\right)$.

\subsubsection{Atividade antioxidante pelo método de sequestro do radical DPPH• (2,2 difenil-1- picrilhidrazina)}

A redução do radical estável DPPH (2,2-difenil-1-picrilhidrazila) foi determinada pelo método colorimétrico utilizando o reagente DPPH [15]. A absorbância foi verificada após $1 \mathrm{~h}$ de incubação no escuro a $25^{\circ} \mathrm{C}$, com leituras realizadas a $515 \mathrm{~nm}$ em espectrofotômetro (Femto, 700 plus).

A eficiência da atividade sequestrante foi calculada de acordo com a Equação (1).

$$
\%=\frac{\left(\mathrm{A}_{\text {controle }}-\mathrm{A}_{\text {amostra }}\right)}{\mathrm{A}_{\text {controle }}} \times 100
$$

onde $\mathrm{A}_{\text {controle: }}$ Absorbância do controle negativo; $\mathrm{A}_{\text {amostra: }}$ Absorbância média da amostra.

O Trolox foi utilizado como padrão para a curva de calibração. Os resultados foram expressos

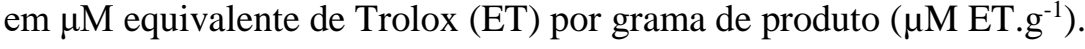

\subsubsection{Atividade antioxidante pelo método do ABTS}

A atividade antioxidante pelo método ABTS foi realizada utilizando os reagentes ABTS (2,2'AZINO - BIS (3-etilbenzo-tiazolina-6-sulfônico) e persulfato de potássio $\left(\mathrm{K}_{2} \mathrm{~S}_{2} \mathrm{O}_{8}\right)$ [16]. A 
absorbância foi verificada em um espectrofotômetro (Femto, 700 plus) a 734 nm após 6 min de incubação a $25^{\circ} \mathrm{C}$. Uma curva de calibração foi preparada utilizando uma solução padrão de Trolox. Os resultados foram expressos em $\mu \mathrm{M}$ equivalente de Trolox (ET) por grama de produto ( $\mu \mathrm{M} \mathrm{ET.g^{- }}$ $\left.{ }^{1}\right)$.

\subsubsection{Atividade antioxidante pelo método de redução do ferro (FRAP)}

A atividade antioxidante pelo método de redução do ferro foi realizada misturando-se os extratos das amostras com o reagente FRAP. Os extratos com o reagente foram mantidos a $37^{\circ} \mathrm{C} \mathrm{em}$ banhomaria por $30 \mathrm{~min}$, e a leitura foi realizada em espectrofotômetro (Femto, 700 plus) a $595 \mathrm{~nm}$. Uma curva de calibração foi preparada utilizando uma solução padrão de Trolox. Os resultados foram expressos em $\mu \mathrm{M}$ equivalente de Trolox (ET) por grama de produto $\left(\mu \mathrm{M} \mathrm{ET} . \mathrm{g}^{-1}\right)$ [17].

\subsection{Aceitabilidade}

As amostras IP0, IP50, IR0 e IR50 foram avaliadas sensorialmente pelo teste de aceitação por 80 provadores não treinados para os atributos cor, aroma, sabor, aparência, aceitação global e intenção de compra. As amostras (aproximadamente $20 \mathrm{~g}$ ) foram servidas de forma monádica, sendo identificadas com três números aleatórios.

Os provadores avaliaram as amostras utilizando a escala hedônica estruturada de 9 pontos, variando de 9 = gostei muitíssimo a $1=$ desgostei muitíssimo, adaptada da metodologia de Meilgaard et al. (1999) [18]. Para a intenção de compra, foi solicitado aos provadores responderem se comprariam ou não o produto, utilizando a escala de 5 pontos, em que $5=$ certamente compraria, $1=$ certamente não compraria.

\subsection{Análise estatística}

Os dados obtidos foram submetidos à análise de variância (ANOVA) e ao teste de comparação de médias de Tukey com 5\% de diferença significativa, com o auxílio do programa estatístico Sisvar 5.6.

A aceitação foi calculada pela relação entre a média das notas atribuídas e a máxima nota atribuída. Quando o valor foi maior que $70 \%$, a amostra foi considerada aceita [19]. Para o cálculo do índice de aceitação (IA), foi utilizada a equação (2).

$$
I A=\frac{A \times 100}{B}
$$

em que $\mathrm{A}=$ nota média obtida para o produto; $\mathrm{B}=$ nota máxima dada ao produto.

\section{RESULTADOS E DISCUSSÃO}

\subsection{Análises físico-químicas}

A Tabela 1 apresenta os valores de acidez, $\mathrm{pH}$, teor de sólidos solúveis e parâmetros de cor das amostras de iogurte. Observou-se que a adição de Spirulina spp. não interferiu na acidez em ácido lático, apresentando valores entre 1,01 e $0,74 \%$. Valores próximos foram apresentados por Malik et al. (2013) [20], que estudaram sobre características da qualidade do iogurte enriquecido com Spirulina spp. em pó, nas concentrações de $0,1 \%, 0,2 \%, 0,3 \%$ e $0,5 \%$. Já para a análise de $\mathrm{pH}$, a adição de Spirulina spp. promoveu o aumento do $\mathrm{pH}$, tanto para o iogurte padrão como para o reconstituído.

Para a análise de cor, avaliando-se o parâmetro luminosidade $\left(\mathrm{L}^{*}\right)$, observou-se que a adição de Spirulina spp. reduziu os valores de luminosidade das amostras, essa relação foi observada tanto para o iogurte padrão quanto para o reconstituído (Tabela 1). A mesma tendência foi constatada por Barkallah et al. (2017) [21], sendo as amostras sem adição de Spirulina spp. (IP0 e IR0) mais claras quando comparadas as demais. Observou-se também que o processo de reconstituição, 
intensificou a cor do iogurte, que apresentou valores menores para o parâmetro a*, indicando maior tendência a coloração verde. Em relação ao parâmetro b* (variação do azul ao amarelo), o aumento do percentual de Spirulina spp. adicionada, reduziu a propensão à coloração amarela.

Tabela 1: Acidez, pH, teor de sólidos solúveis e parâmetros de cor das amostras de iogurte.

\begin{tabular}{ccccccc}
\hline & $\begin{array}{c}\text { Acidez em } \\
\text { ácido lático } \\
(\%)\end{array}$ & $\mathrm{pH}$ & TSS ( ${ }^{\mathrm{o}}$ Brix $)$ & $\mathrm{L}^{*}$ & $\mathrm{a}^{*}$ & $\mathrm{~b}^{*}$ \\
& & & & & \\
\hline IP0 & $0,74^{\mathrm{a}} \pm 0,03$ & $4,53^{\mathrm{b}} \pm 0,02$ & $12,06^{\mathrm{b}} \pm 0,71$ & $93,64^{\mathrm{a}} \pm 0,68$ & $-7,05^{\mathrm{b}} \pm 0,01$ & $15,33^{\mathrm{b}} \pm 0,07$ \\
IP25 & $0,74^{\mathrm{a}} \pm 0,03$ & $4,61^{\mathrm{a}} \pm 0,03$ & $13,06^{\mathrm{b}} \pm 0,71$ & $73,45^{\mathrm{b}} \pm 3,10$ & $-11,43^{\mathrm{a}} \pm 0,35$ & $6,19^{\mathrm{d}} \pm 0,34$ \\
IP50 & $0,80^{\mathrm{a}} \pm 0,01$ & $4,66^{\mathrm{a}} \pm 0,03$ & $14,06^{\mathrm{b}} \pm 0,71$ & $69,26^{\mathrm{b}} \pm 0,98$ & $-11,98^{\mathrm{a}} \pm 0,06$ & $5,32^{ \pm} \pm 0,18$ \\
IR0 & $0,84^{\mathrm{a}} \pm 0,01$ & $4,36^{\mathrm{c}} \pm 0,03$ & $21,06^{\mathrm{a}} \pm 0,71$ & $89,12^{\mathrm{a}} \pm 2,21$ & $-7,95^{\mathrm{c}} \pm 0,05$ & $16,53^{\mathrm{a}} \pm 0,51$ \\
IR25 & $0,96^{\mathrm{a}} \pm 0,19$ & $4,49^{\mathrm{b}} \pm 0,01$ & $23,06^{\mathrm{a}} \pm 0,71$ & $62,45^{\mathrm{cd}} \pm 1,49$ & $-11,89^{\mathrm{d}} \pm 0,10$ & $7,26^{\mathrm{a}} \pm 0,16$ \\
IR50 & $1,01^{\mathrm{a}} \pm 0,03$ & $4,61^{\mathrm{a}} \pm 0,02$ & $21,06^{\mathrm{a}} \pm 0,71$ & $56,71^{\mathrm{cd}} \pm 0,74$ & $-13,18^{\mathrm{d}} \pm 0,02$ & $6,76^{\mathrm{cd}} \pm 0,02$ \\
\hline
\end{tabular}

As médias seguidas pela mesma letra, na coluna, não diferem entre si a p<0,05. IP0 - iogurte padrão; IP25 - iogurte padrão com 0,25\% de Spirulina spp.; IP50 - iogurte padrão com 0,50\% de Spirulina spp.; IRO iogurte reconstituído; IR25 - iogurte reconstituído com 0,25\% de Spirulina spp.; IR50 - iogurte reconstituído com 0,50\% de Spirulina spp.

A Tabela 2 apresenta os valores de cinzas, lipídeos, proteínas e carboidratos das amostras de iogurte. Na análise de cinzas, observou-se que ao adicionar Spirulina spp., houve diferença apenas entre as amostras IP0 e IR50, indicando que a Spirulina spp. possui alto teor de matéria mineral. O mesmo resultado foi notado por Barkallah et al. (2017) [21], que analisaram o efeito da adição da Spirulina spp. no iogurte sobre as propriedades físico-químicas, de textura, propriedades antioxidantes e sensoriais durante a fermentação e armazenamento. No caso de cinzas, Barkallah et al. (2017) [21] analisaram o iogurte padrão (sem Spirulina spp.) e o adicionado de 0,25\% de Spirulina spp.

Tabela 2: Teor de cinzas, lipídeos, proteínas e carboidratos das amostras de iogurte.

\begin{tabular}{cccccc}
\hline & Cinzas (\%) & Lipídeos (\%) & Proteína (\%) & Umidade (\%) & Carboidratos (\%) \\
\hline IP0 & $0,85^{\mathrm{b}} \pm 0,01$ & $3,75^{\mathrm{a}} \pm 0,27$ & $3,66^{\mathrm{d}} \pm 0,05$ & $79,49^{\mathrm{c}} \pm 0,42$ & $12,25^{\mathrm{c}} \pm 1,56$ \\
IP25 & $0,92^{\mathrm{a}} \pm 0,10$ & $2,89^{\mathrm{a}} \pm 2,07$ & $3,6^{\mathrm{d}} \pm 0,04$ & $80,69^{\mathrm{a}} \pm 0,01$ & $11,81^{\mathrm{a}} \pm 1,56$ \\
IP50 & $1,01^{\mathrm{a}} \pm 0,09$ & $3,71^{\mathrm{a}} \pm 0,30$ & $4,14^{\mathrm{a}} \pm 0,01$ & $80,24^{\mathrm{a}} \pm 0,02$ & $10,90^{\mathrm{f}} \pm 1,56$ \\
IR0 & $0,93^{\mathrm{ab}} \pm 0,02$ & $4,85^{\mathrm{a}} \pm 0,13$ & $5,34^{\mathrm{a}} \pm 0,03$ & $74,06^{\mathrm{d}} \pm 0,48$ & $15,07^{\mathrm{a}} \pm 1,56$ \\
IR25 & $0,99^{\mathrm{a}} \pm 0,09$ & $5,81^{\mathrm{a}} \pm 0,06$ & $5,09^{\mathrm{b}} \pm 0,01$ & $75,82^{\mathrm{b}} \pm 0,03$ & $12,23^{\mathrm{d}} \pm 1,56$ \\
IR50 & $1,06^{\mathrm{a}} \pm 0,03$ & $5,35^{\mathrm{a}} \pm 0,37$ & $5,15^{\mathrm{b}} \pm 0,08$ & $75,93^{\mathrm{b}} \pm 0,15$ & $12,31^{\mathrm{b}} \pm 1,56$ \\
\hline
\end{tabular}

As médias seguidas pela mesma letra, na coluna, não diferem entre si a $p<0,05$. IP0 - iogurte padrão; IP25 - iogurte padrão com 0,25\% de Spirulina spp.; IP50 - iogurte padrão com 0,50\% de Spirulina spp.; IRO iogurte reconstituído; IR25 - iogurte reconstituído com 0,25\% de Spirulina spp.; IR50 - iogurte reconstituído com 0,50\% de Spirulina spp.

A adição de Spirulina spp. não interferiu no teor de lipídeos (Tabela 2) do iogurte, não apresentando diferença significativa, sendo observado o mesmo no estudo de Barkallah et al. (2017) [21]. A adição de Spirulina spp. aumentou o teor proteico das amostras IP25 e IP50. Observou-se que, em geral, as amostras reconstituídas apresentaram maiores teores, em média $35 \%$, quando comparadas ao iogurte padrão. Tal fato pode estar correlacionado ao menor teor de umidade das amostras reconstituídas (em média 75\%) quando comparadas às amostras padrões (em média 80\%). De acordo com Beheshtipour et al. (2012) [22], Spirulina spp. é a espécie de microalga mais conhecida por apresentar elevado teor proteico, cerca de 65\%. Nos estudos de Debbabi et al. (2017) [23], a adição de Spirulina spp. em iogurtes proporcionou acréscimo de proteína, sendo que os autores indicaram que este é um dos fatores nutricionais e físico-químicos essenciais para a escolha do produto lácteo no momento da compra.

Constatou-se que a adição de Spirulina spp. ao produto provocou aumento no teor de umidade, sendo que o iogurte reconstituído obteve umidade inferior ao iogurte padrão. Isso se deve provavelmente porque a reconstituição do iogurte não foi realizada na mesma proporção da 
quantidade de água retirada no processo de secagem, entretanto a quantidade de água adicionada foi realizada visando uma textura mais próxima ao iogurte padrão. Tal fato pode ser correlacionado com o teor de sólidos solúveis ( ${ }^{\circ}$ Brix), em que se verificou diferença entre as amostras padrão e as reconstituídas (Tabela 1). A adição de spirulina, promoveu o aumento do teor de sólidos solúveis das amostras, conforme previsto por Malik et al. (2013) [20]. O teor de carboidrato das amostras diminuiu.

\subsection{Análises de compostos fenólicos totais e atividade antioxidante}

A Tabela 3 apresenta os valores de TPC e atividade antioxidante pelos métodos DPPH, ABTS e FRAP. Na análise de TPC, observou-se que houve diferença significativa entre as amostras padrões e reconstituídas, os maiores valores foram obtidos nas amostras de iogurte reconstituído nas duas concentrações avaliadas $(0,25 \%$ e $0,50 \%)$. Possivelmente, este fato está relacionado à presença de compostos fenólicos na Spirulina spp., como ácidos orgânicos: ácidos caféico, clorogênico, salicílico, sináptico e trans-cinâmico, os quais agem sinergicamente como compostos antioxidantes em sistemas in vivo e in vitro [24].

Tabela 3: TPC, DPPH, ABTS e FRAP das amostras de iogurte padrão e reconstituído.

\begin{tabular}{ccccc}
\hline & TPC $^{\mathrm{I}}$ & DPPH $^{\mathrm{II}}$ & ABTS $^{\mathrm{III}}$ & FRAP $^{\text {IV }}$ \\
\hline IP0 & $19,35^{\mathrm{c}} \pm 0,62$ & $445,19^{\mathrm{c}} \pm 4,22$ & $107,65^{\mathrm{d}} \pm 11,89$ & $219,55^{\mathrm{d}} \pm 3,46$ \\
IP25 & $21,42^{\mathrm{c}} \pm 0,79$ & $446,00^{\mathrm{c}} \pm 2,81$ & $125,24^{\mathrm{d}} \pm 3,81$ & $243,99^{\mathrm{cd}} \pm 3,46$ \\
IP50 & $19,99^{\mathrm{c}} \pm 0,82$ & $452,07^{\mathrm{c}} \pm 9,13$ & $148,33^{\mathrm{c}} \pm 1,90$ & $267,94^{\mathrm{c}} \pm 16,56$ \\
IR0 & $35,02^{\mathrm{b}} \pm 1,21$ & $478,78^{\mathrm{b}} \pm 6,57$ & $251,67^{\mathrm{b}} \pm 1,90$ & $341,81^{\mathrm{b}} \pm 1,15$ \\
IR25 & $38,82^{\mathrm{a}} \pm 1,59$ & $515,08^{\mathrm{a}} \pm 4,52$ & $286,86^{\mathrm{a}} \pm 15,23$ & $439,61^{\mathrm{a}} \pm 1,15$ \\
IR50 & $41,42^{\mathrm{a}} \pm 0,89$ & $509,66^{\mathrm{a}} \pm 3,84$ & $308,85^{\mathrm{a}} \pm 15,11$ & $437,98^{\mathrm{a}} \pm 12,68$ \\
\hline
\end{tabular}

As médias seguidas pela mesma letra, na coluna, não diferem entre si a $p<0,05$. IP0 - iogurte padrão; IP25 - iogurte padrão com 0,25\% de Spirulina spp.; IP50 - iogurte padrão com 0,50 \% de Spirulina spp.; IR0 iogurte reconstituído; IR25 - iogurte reconstituído com 0,25\% de Spirulina spp.; IR50 - iogurte reconstituído com 0,50 \% de Spirulina spp. I- mgEAG. $g^{-1}$ produto; II, III, IV - $\mu M E T . g^{-1}$ produto.

A adição de Spirulina spp. nas amostras de iogurte promoveu o aumento da capacidade antioxidante, constatando e comprovando seu poder antioxidante [25]. Em um estudo recente, também foi observado o aumento da atividade antioxidante de iogurte adicionado de $0,25 \%$ de Spirulina spp. pelos métodos DPPH e FRAP [21].

Em geral, avaliando os diferentes processos, observou-se que em todos os casos, tanto para TPC quando para atividade antioxidante (DPPH, ABTS e FRAP) as amostras reconstituídas apresentaram maiores teores quando comparadas as amostras denominadas padrão, as quais não sofreram o processo de liofilização, destacando-se que este fator pode estar relacionado ao menor teor de umidade do iogurte reconstituído. Avaliando as diferentes concentrações em cada processo, observou-se que no caso do iogurte reconstituído não foi observada diferença significativa, entretanto para as amostras padrão nas metodologias de ABTS e FRAP as amostras com 0,50\% de adição apresentaram os maiores valores. Assim, por este motivo, para a próxima etapa deste trabalho, optou-se por realizar o teste de aceitação com as amostras que apresentaram maior atividade antioxidante (IP50 e IR50) e compará-las com as amostras sem adição de Spirulina spp. (IP0 e IR0).

\subsection{Aceitabilidade}

A Tabela 4 apresenta as médias obtidas pelo teste de aceitação das amostras de iogurte padrão e reconstituído. Amostra IR0 obteve melhores notas em todos os critérios avaliados, sugerindo que o processo de liofilização melhorou as características sensoriais do produto nas condições avaliadas. As amostras com a adição de Spirulina spp. tiveram menor aceitação, provavelmente devido a sua coloração e sabor diferencial. O sabor acentuado causado pela adição de Spirulina spp. pode estar relacionado aos compostos gerados da oxidação de lipídeos, assim como minerais que não só agem como moléculas pró-oxidantes, mas também podem produzir aromas [26]. Cita- 
se que trabalhos futuros podem ser realizados e como alternativa para mascarar o sabor da Spirulina spp., indica-se a adição de saborizantes e aromatizantes.

Tabela 4: Teste de aceitação das amostras de iogurte padrão e reconstituído.

\begin{tabular}{cccccccc}
\hline & Cor & Aroma & Sabor & Aparência & $\begin{array}{c}\text { Aceitação } \\
\text { Global }\end{array}$ & $\begin{array}{c}\text { Intenção de } \\
\text { compra }\end{array}$ & $\begin{array}{c}\text { Índice de } \\
\text { aceitabilidade } \\
\text { para Aceitação } \\
\text { Global }\end{array}$ \\
\hline IP0 & $7,59^{\mathrm{a}}$ & $7,05^{\mathrm{b}}$ & $6,47^{\mathrm{b}}$ & $7,33^{\mathrm{b}}$ & $6,74^{\mathrm{b}}$ & $3,13^{\mathrm{b}}$ & 74,89 \\
IP50 & $5,63^{\mathrm{b}}$ & $6,45^{\mathrm{bc}}$ & $5,97^{\mathrm{cd}}$ & $5,74^{\mathrm{b}}$ & $5,99^{\mathrm{c}}$ & $2,75^{\mathrm{b}}$ & 66,56 \\
IR0 & $7,81^{\mathrm{a}}$ & $7,74^{\mathrm{a}}$ & $7,92^{\mathrm{a}}$ & $7,91^{\mathrm{a}}$ & $7,95^{\mathrm{a}}$ & $4,36^{\mathrm{a}}$ & 88,33 \\
IR50 & $5,47^{\mathrm{b}}$ & $6,27^{\mathrm{c}}$ & $5,74^{\mathrm{c}}$ & $5,64^{\mathrm{a}}$ & $5,79^{\mathrm{c}}$ & $2,77^{\mathrm{b}}$ & 64,33 \\
\hline
\end{tabular}

As médias seguidas pela mesma letra, na coluna, não diferem entre si a p $<0,05$. IP0 - iogurte padrão; IP25 - iogurte padrão com 0,25\% de Spirulina spp.; IP50 - iogurte padrão com 0,50 \% de Spirulina spp.; IRO iogurte reconstituído; IR25 - iogurte reconstituído com 0,25\% de Spirulina spp.; IR50 - iogurte reconstituído com 0,50 \% de Spirulina spp.

É fundamental avaliar a aceitabilidade quando se desenvolve um novo produto, com o intuito de estudar seu comportamento no mercado consumidor [27]. Segundo Dutcosky (2013) [19], de acordo com as propriedades sensoriais, para que o produto seja considerado como aceito é necessário que este obtenha um Índice de Aceitabilidade (IA) de $70 \%$, no mínimo.

Com base nas notas para a aceitabilidade e no cálculo do IA, verificou-se que os iogurtes IP0 e IR0 foram considerados aceitos pelos provadores; e que o reconstituído (IR0) apresentou maior percentual de aceitabilidade. Apesar dos valores obtidos pelo teste de aceitação serem em torno de $26 \%$ menores para os iogurtes adicionados de $0,50 \%$ de Spirulina spp. quando comparados às outras amostras, os mesmos possuem melhores características antioxidantes e nutricionais, sendo estes fatores importantes na determinação da escolha do produto. Assim, sugere-se a realização de trabalhos futuros, como adição de saborizantes no iogurte e/ou o uso de diferentes concentrações de Spirulina spp. para melhoria da qualidade sensorial do produto.

\section{CONCLUSÃO}

A adição da microalga Spirulina spp. contribui para o aumento do teor de compostos fenólicos e atividade antioxidante dos iogurtes, bem como para o aumento de proteínas. O iogurte reconstituído sem adição de Spirulina spp. apresentou melhor aceitabilidade de acordo com teste de aceitação.

\section{REFERÊNCIAS BIBLIOGRÁFICAS}

1. Morais RMSC, Morais AMMB, Dammak I, Bonilla J, Sobral PJA, Laguerre J-C, Afonso MJ, Ramalhosa ECD. Functional dehydrated foods for health preservation. J Food Qual. 2018 Feb;2018:1-29, doi.org/10.1155/2018/1739636.

2. Gahruie HH, Eskandari MH, Mesbahi G, Hanifpour MA. Scientific and technical aspects of yogurt fortification: A review. Food Sci Hum Wellness. 2015 Mar;4(1):1-8, doi.org/10.1016/j.fshw.2015.03.002.

3. Sadhu SP. Effect of cold chain interruptions on the shelf-life of fluid pasteurised skim milk at the consumer stage. Braz J Food Technol. 2018 Mar;21:e2017064, doi.org/10.1590/1981-6723.06417.

4. Mishra BP, Chauhan G, Mendiratta SK, Sharma BD, Desai BA, Rath PK. Development and quality evaluation of dehydrated chicken meat rings using spent hen meat and different extenders. J Food Sci Technol. 2015 Apr;52(4):2121-9, doi: 10.1007/s13197-013-1197-2.

5. Marques LG, Prado MM, Freire JT. Rehydration characteristics of freeze-dried tropical fruits. LWT Food Sci Technol. 2009 Sep;42(7):1232-7, doi.org/10.1016/j.lwt.2009.02.012.

6. Ojha KS, Tiwari BK. Novel food fermentation technologies.Switzerland:Springer International Publishing; 2016.Chapter 2, Novel preservation techniques for microbial cultures; p. 7-34, doi: 10.1007/978-3-319-42457-6_1. 
7. Shao A, Drewnowski A, Willcox DC, Krämer, L, Lausted C, Eggersdorfer M, Mathers J, Bell JD, Randolph RK, Witkamp R, Griffiths JC. Optimal nutrition and the ever-changing dietary landscape: a conference report. Eur J Clin Nutr. 2017 May;56(1):1-21, doi: 10.1007/s00394-017-1460-9.

8. Furmaniak MA, Misztak AE, Franczuk MD, Wilmotte A, Waleron M, Waleron KF. Edible cyanobacterial genus Arthrospira: actual state of the art in cultivation methods, genetics, and application in medicine. Front Microbiol. 2017 Dec;8:2541, doi: 10.3389/fmicb.2017.02541.

9. Morais MG, Vaz BS, Morais EG, Costa JAV. Biologically active metabolites synthesized by Microalgae. Biomed Res Int. 2015 Aug;2015:835761, doi: 10.1155/2015/835761.

10. Nuhu AA. Spirulina (Arthrospira): An important source of nutritional and medicinal compounds. J Mar Biol. 2013 Apr;2013:325636, doi.org/10.1155/2013/325636.

11. IAL - Instituto Adolfo Lutz. Métodos físico-químicos para análise de alimentos. Coordenadores Zenebon O, Pascuet NS, Tiglea P. 4. ed. São Paulo: Instituto Adolfo Lutz, 2008. 1020 p.

12. Zulueta A, Maurizi A, Frígola A, Esteve MJ, Coli R, Burini G. Antioxidant capacity of cow milk, whey and deproteinized milk. Int Dairy J. 2009Jul;19:380-5, doi.org/10.1016/j.idairyj.2009.02.003.

13. Cutler P. Protein Purification Protocols. Methods in molecular biology. 2nd ed. Totowa (United States): Humana Press Inc; 2004.Chapter 8, The extraction of enzymes from plant tissues rich in phenolic compounds, p. 65-74, doi: 10.1385/1-59259-655-x:65.

14. Singleton VL, Rossi JA. Colorimetry of total phenolics with phosphomolybdic-phosphotungstic acid reagents. Am J Enol Viticult. 1965 Jan;16(3):144-58.

15. Thaipong K, Boonprakob U, Crosby K, Cisneros-Zevallos L, Byrne DH. Comparison of ABTS, DPPH, FRAP, and ORAC assays for estimating antioxidant activity from guava fruit extracts. J Food Compos Anal. 2006 Nov;19:669-75, doi.org/10.1016/j.jfca.2006.01.003.

16. Nenadis N, Wang LF, Tsimidou M, Zhang HY. Estimation of scavenging activity of phenolic compounds using the ABTS+ assay. J Agric Food Chem. 2004 Jul;52(15):4669-74, doi.org/10.1021/jf0400056.

17. Pulido R, Bravo L, Saura-Calixto F. Antioxidant activity of dietary polyphenols as determined by a modified ferric reducing/ antioxidant power assay. J Agric Food Chem. 2000 Aug;48(8):3396-402, doi: 10.1021/jf9913458.

18. Meilgaard M, Civille GV, Carr BT. Sensory evaluation techniques. 3 ed. New York: CRC Press; 1999. $387 \mathrm{p}$.

19. Dutcosky SD. Análise sensorial de alimentos. 4. ed. Curitiba: Champagnat; 2013. 531 p.

20. Malik P, Kempanna C, Murthy N, Anjum. Quality characteristics of yoghurt enriched with Spirulina powder. Mysore J Agric Sci. 2013 Apr;47(2):354-9.

21. Barkallah M, Dammak M, Louati I, Hentati F, Hadrich B, Mechichi T, Ayadi M A, Fendri I, Attia H, Abdelkafi, S. Effect of Spirulina platensis fortification on physicochemical, textural, antioxidant and sensory properties of yogurt during fermentation and storage. LWT - Food Sci Technol. 2017 Oct;:84:323-330, doi.org/10.1016/j.lwt.2017.05.071.

22. Beheshtipour H, Mortazavian AM, Haratian P, Darani KK. Effects of Chlorella vulgaris and Spirulina platensis addition on viability of probiotic bacteria in yogurt and its biochemical properties. Eur Food Res Technol. 2012 Oct;235(4):719-28, doi: 10.1007/s00217-012-1798-4.

23. Debbabi H, Boubaker B, Gmati T, Chouaibi M, Boubaker A, Snoussi A. Yogurt enrichment with Spirulina (Arthrospira platensis): effect of storage on physicochemical parameters. In: Kallel A, Ksibi M, Ben Dhia H, Khélifi N. (eds) Recent advances in environmental science from the euro-mediterranean and surrounding regions. EMCEI 2017. Advances in science, technology \& innovation (IEREK Interdisciplinary Series for Sustainable Development). Springer, Cham. 2018. p. 1267-1268.

24. Souza TD, Prietto L, Souza MM, Furlong EB. Profile, antioxidant potential, and applicability of phenolic compounds extracted from Spirulina platensis. Afr J Biotechnol. 2015 Oct;14(41):2903-9, doi:10.5897/AJB2015.14926.

25. Yamaguchi SKF, Moreira JB, Costa JAV, Souza CKde, Bertoli SL, Carvalho LF de. Evaluation of adding Spirulina to freeze-dried yogurts before fermentation and after freeze-drying. Ind Biotechnol. 2019Apr;15(2):89-94,doi.org/10.1089/ind.2018.0030.

26. Shimamatsu H. Mass production of Spirulina, an edible microalga. Hydrobiologia. 2004 Jan;512(1-3):3944, doi.org/10.1023/B:HYDR.0000020364.23796.04.

27. Sharif MK, Butt MS, Sharif HR, Nasir M. Sensory evaluation and consumer acceptability. In: Handbook of Food Science and Technology. 2017. Chapter 14, 361-386. 